

\section{La campiña y La Loma: huella, memoria y vida}

Marcelino Sánchez Ruiz', arqueólogo; Ana Coronado Sánchez, arquitecta
Las suaves estribaciones de la vieja Sierra Morena y las jóvenes serranías subbéticas se anudan en este territorio de la campiña de Jaén y Las Lomas de Úbeda a través del escenario natural que ofrece el amplio valle del alto Guadalquivir.

Este encuentro entre sierras articuladas a través del valle tiene una localización geográfica a medio camino entre el triángulo que conforman Sevilla-Madrid-Valencia y constituye uno de sus principales valores territoriales. Esta condición le ha permitido ser históricamente elemento de conexión entre el levante y el sur de Andalucia occidental a través del valle del Guadalquivir y de la submeseta sur y el sur de Andalucia oriental a través del surco intrabético que se abre paso entre Sierra Mágina y la sierra de Cazorla, Segura y las Villas.

La condición de articulación de los tres sistemas territoriales más amplios de Andalucia como lugar de paso y de encuentro ha ido configurando progresivamente la identidad de este territorio marcado por la diversidad cultural, que se hace perceptible a través de su patrimonio, su paisaje y la cultura territorial de sus habitantes como más primario y complejo patrimonio inmaterial de una sociedad (OJEDA RIVERA; SILVA PÉREZ, 2002).

Este territorio forma parte de una de las "coyunturas" territoriales más significativas de la península ibérica. Podemos distinguir varias unidades territoriales, cada una con su singularidad propia, pero todas configurando una red de implicaciones compartidas con el valle del Guadalquivir y sus afluentes como elementos articuladores.

Al norte, el piedemonte de Sierra Morena, con sus pizarras y esquistos y su cultura minera, la sabiduría de la dehesa y la jara y con enclaves fundamentales en el pasado y en el presente como Linares o Bailén, que van ocupando las suaves estribaciones del sur de Sierra Morena en su encuentro con el valle.

Las estribaciones de Sierra Morena de dirección NE-SO se van tumbando progresivamente hasta conformar La Loma, como un gran interfluvio que adquiere autonomía en su elevación alargada este-oeste, entre el río Guadalimar (400 m s.n.m.), al norte, y el Guadalquivir, al sur (350 m s.n.m.), sobre el que se asoma como un gran espolón.

En su mesa, tiene una altitud media de unos $750 \mathrm{~m}$ y se configura como una sucesión de colinas delimitadas por los cauces de los arroyos que, desde lo alto, buscan los valles descendiendo suavemente hacia el Guadalquivir y con pendientes más pronunciadas hacia el Guadalimar.

Al suroeste, la fértil campiña andaluza se prolonga hasta encontrarse, más al sur, con el piedemonte de las sierras de Jabalcuz y Mágina. Es un espacio de continuidad, con pequeñas terrazas configuradas por cauces que producen un espacio fértil hasta su confluencia con el río Guadalquivir. Los enclaves se van sucediendo en estos interfluvios en altitudes similares, en torno a los 500 m, descendiendo levemente hacia el valle.

En el borde sur de la campiña, al pie de la sierra de Jabalcuz, se eleva Jaén, en torno a la cota 560 m, en un emplazamiento privilegiado que salva amplios desniveles desde el castillo de Santa Catalina en su parte más alta hasta la campiña.

Al sureste, la cabecera del Guadalquivir y del sistema subbético se recorta en sucesión de picos calizos y masas de pinos de las sierras de Cazorla y las Villas al este, y Sierra Mágina al sur, cerrando el fondo escénico con las nieves de los más de 2.000 m s.n.m.

Entre tanta montaña abrupta, el río Guadiana Menor se abre paso y pone en contacto el alto Guadalquivir con la depresión Guadix-Baza y el altiplano granadino. El propio Guadalquivir, a partir de Úbeda y Baeza, comienza a abrirse en un verdadero valle de "río grande", fortalecido por los aportes que le trae el Guadiana Menor.

A nivel geomorfológico, parece que sirviera para encauzar, hacia el sur-oeste, los débiles inicios de nuestro río grande, y permitien- 


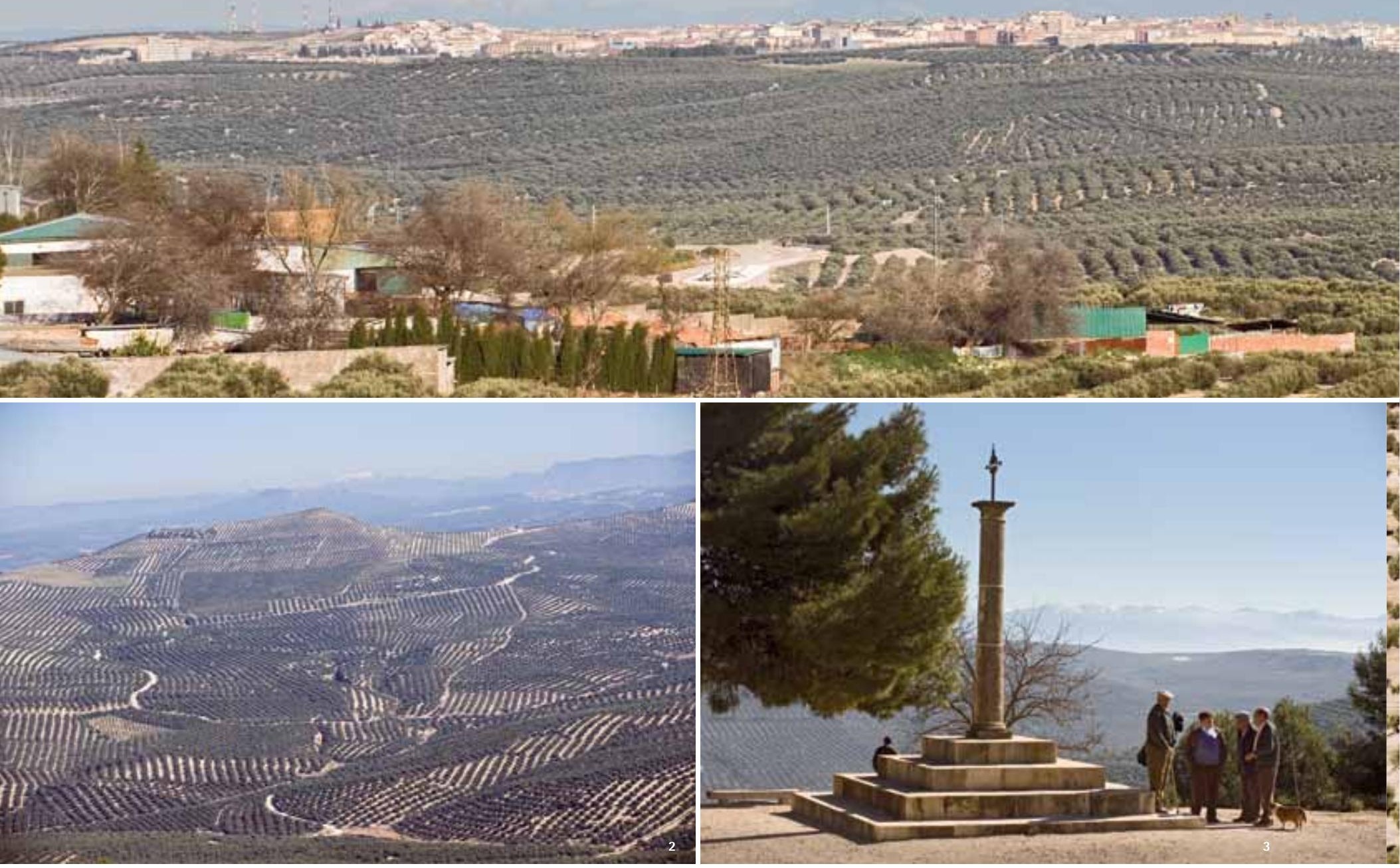

1. Úbeda desde Baeza

2 y 3. Mirador de Sabiote

do el desarrollo hacia el Atlántico de esa columna vertebral de agua que articula Andalucia, produciendo además el encuentro en su valle entre los cultivos de secano y los de regadío.

La diversidad propia de un territorio de encuentro entre las sierras y la campiña, rico en espacios adehesados y cultivos cerealísticos que se han combinado tradicionalmente con el olivar, ha ido dando paso progresivamente al cultivo dominante del olivo como ejemplo de la permanente transformación del paisaje.

Hoy, el mar de olivos ocupa prácticamente el 90\% del suelo cultivable de este territorio, por lo que el impacto que provoca en quien lo observa es enormemente significativo, con las geometrías variables de las parcelas, los tonos de color verde diverso, unas veces recortados sobre la arcilla clara -hacia el Guadalquivir- o rojiza -hacia el Guadalimar-, o cambiando el tono según la hora del día o la luz que reciban. Siempre, la alternancia de líneas rectas, paralelas o de masas de olivos raseados y uniformes, según la altura desde la que se observen.

En relación con la ocupación humana de estos territorios, conocida desde la más remota antigüedad, la sucesión de hábitats humanos confirma la capacidad de este espacio fértil de la vega y de fácil protección de las lomas de aportar recursos para su explotación de manera generosa, generándose una cultura te- 


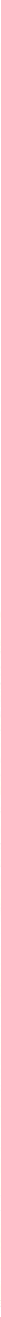

4 y 5 . Pegalajar.

Fuente: Fondo Gráfico IAPH

rritorial propia con relación a las formas de cultivo, la manera de gestionar el agua, la minería, etc.

Este mar de olivos ha aportado y exportado una cultura culinaria medicinal y arquitectónica así como una memoria a través de sus cortijos y de sus haciendas, o la cultura que se hace presente en la alfareria asociada a la producción del aceite desde la época romana a través de las ánforas.

Antes de este "continuum" de olivar, de este bosque antrópico tan enorme y extenso, que ocupa prácticamente todo el espacio cultivable, este territorio era una especie de paradigma de la trilogía mediterránea, donde el olivar, los cereales y la vid manchaban la campiña y las lomas, con ese dinamismo colorista de alternancias geométricas, combinadas con la producción de la dehesa con sus claros y masas arbóreas.

Se trata de un espacio antropizado desde hace más de 6.000 años. Los datos aportados por los diferentes análisis de polen realizados en el marco del proyecto de investigación arqueológica El Alcázar de Úbeda nos evidencian unas transformaciones del paisaje que existían antes de la ocupación de los primeros agricultores en esta zona del alto Guadalquivir.

Un bosque mediterráneo denso cuya deforestación para obtener más tierras de cultivo o nuevos pastos, la sobreexplotación del 
pastoreo y el consumo para combustible o material de construcción han hecho que desde muy antiguo se haya visto alterado sustancialmente; tanto, que ahora sea un reducto en forma de islas más o menos densas y poco extensas repartidas en el entorno de las cuencas del Guadiana y del Guadalquivir.

En todo ese proceso, hay algo especialmente significativo que podria hacer replantear los orígenes de la presencia del olivo cultivado en esta parte del Mediterráneo occidental.

Parece demostrarse que las mismas manos que durante milenios, conscientemente, deforestan especies como los pinos, las encinas, los robles, los quejigos o los árboles de ribera, etc., son las que no alteran la presencia del olivo silvestre en los mismos lugares. Ello nos coloca ante la necesidad de continuar estudiando la posibilidad de entender que el acebuche es preservado y mantenido, mientras que se permite o se provoca la deforestación de las demás especies.

La romanización aporta la consolidación de la trilogía mediterránea, el reparto de parcelas de tierra a las legiones y la colonización romana en fundus a lo largo del valle del Guadalquivir y sus principales afluentes. También la articulación de caminos y núcleos urbanos, que son superposiciones y reutilizaciones de muchos de los oppida ibéricos que se construyeron en el s. V a. de C., y especialmente en el IV, distribuidos a lo largo del valle y que fueron uno de los escenarios principales del choque de las superpotencias mediterráneas del momento: Cartago y Roma.

Este territorio se organiza en un proceso de colonización agrícola y minera a través de ciudades que adquieren gran importancia como Obulco (Porcuna), Biatia (Baeza) y fundamentalmente Cástulo (Linares), que conectará a través de la Via Augusta el valle del Guadalquivir con Levante.

Con la presencia musulmana este espacio cobra un nuevo sentido por su capacidad de control territorial en esta coyuntura de caminos. Se plantea una estrategia de concentración en aquellos núcleos que por su posición topográfica son fácilmente defendibles al tiempo que gozan de la posibilidad de visualizar las vías de penetración por el valle del Guadalquivir y el surco intrabético (OJEDA RIVERA; SILVA PÉREZ, 2002).

Serán los espolones amesetados del borde de la plataforma alta de La Loma los lugares seleccionados para la implantación de las poblaciones principales, en forma de qalath o castillos que evolucionan según su incremento de población, convirtiéndose en medinas amuralladas, que siempre reservan de ocupación masiva las laderas con mayor insolación.

Generan un sofisticado sistema de aprovechamiento del agua para riego, tanto de las surgencias naturales a modo de fuentes, o mediante la captación de agua a través de pozos, minados y aljibes, de forma que convierten las sucesivas plataformas de tie- rras arcillosas en verdaderos vergeles que han continuado hasta nuestros dias, especialmente utilizadas aún hoy en Úbeda y Baeza y que configuran también su impronta paisajistica.

La multitud de torres y castillos fortificados asi como los topónimos de los pueblos que jalonan la campiña (Torredonjimeno o Torredelcampo) nos hablan de la condición de frontera entre el reino cristiano y Al-Andalus, que durante gran cantidad de tiempo tuvo esta franja del territorio andaluz (OJEDA RIVERA; SILVA PÉREZ, 2002).

La implantación de esos castillos y la ampliación con construcciones alrededor han configurado la imagen actual de los pueblos y ciudades, determinada precisamente por la existencia de agua en abundancia en esos bordes altos, fácilmente defendibles, con tierras cultivables, que siendo aprovechadas desde la cultura agrícola anterior y la hispanomusulmana, definen hasta hoy su imagen.

El uso de la piedra arenisca, fácil de trabajar para la construcción de sólidas edificaciones de todo tipo, ha sido otra clave que caracteriza nuestro territorio en cuanto a asentamientos poblacionales se refiere, pues la impronta urbana tiene ciertas similitudes, no solamente topológicas y topográficas, sino también morfológicas, especialmente en los asentamientos que se conforman en el inicio de la Edad Media, con murallas que rodean el caserío.

Un castillo del que se abren los lienzos amurallados y las torres y las puertas que dejan paso a los caminos que conectan los puntos cardinales para formar una red tupida de relaciones intraterritoriales y entre este territorio y las grandes zonas geográficas de su entorno.

Esas huellas hacen de La Loma y la campiña enclaves privilegiados de articulación territorial entre los paisajes de las sierras subbéticas, Sierra Morena, el amplio valle del Guadalquivir y el Guadalimar, el grande y el rojo, el wadi al-quevir y el wadi al- imar, poniendo en contacto los caminos que han hecho posibles los grandes intercambios, los grandes impulsos civilizadores o conquistadores de Andalucía.

Esos caminos aún hoy tienen presencia entre nosotros y en nuestro paisaje territorial, pero también urbano, pues especialmente singular es la eclosión renacentista, que tanto aportó a la modernización de la mentalidad y de los espacios urbanos de Úbeda y Baeza, por lo que supuso una aportación definitiva a la entrada del pensamiento humanista en España, y que tanto cambió también los otros paisajes urbanos, transformando la imagen medieval.

\footnotetext{
1. Úbeda

2. Plaza de Santa María en Baeza

3. Puerta de Jaén en Baeza

4. Sacra Capilla del Salvador de Úbeda

5. Úbeda desde el Ayuntamiento.

Fuente: Fondo Gráfico IAPH
} 

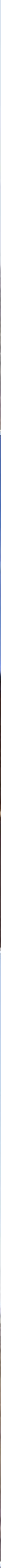

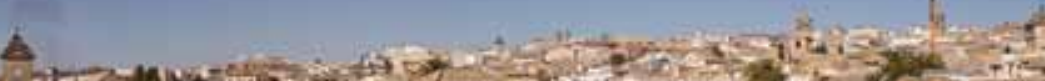

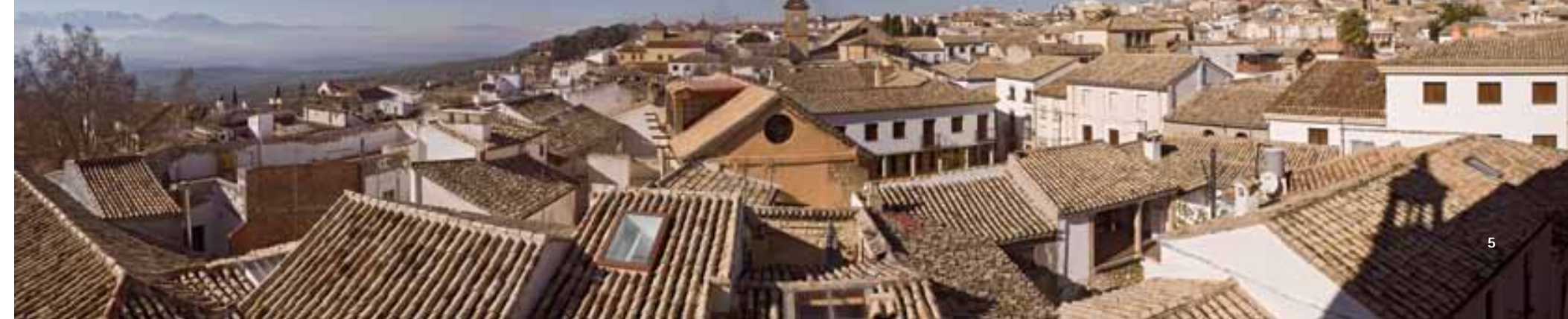




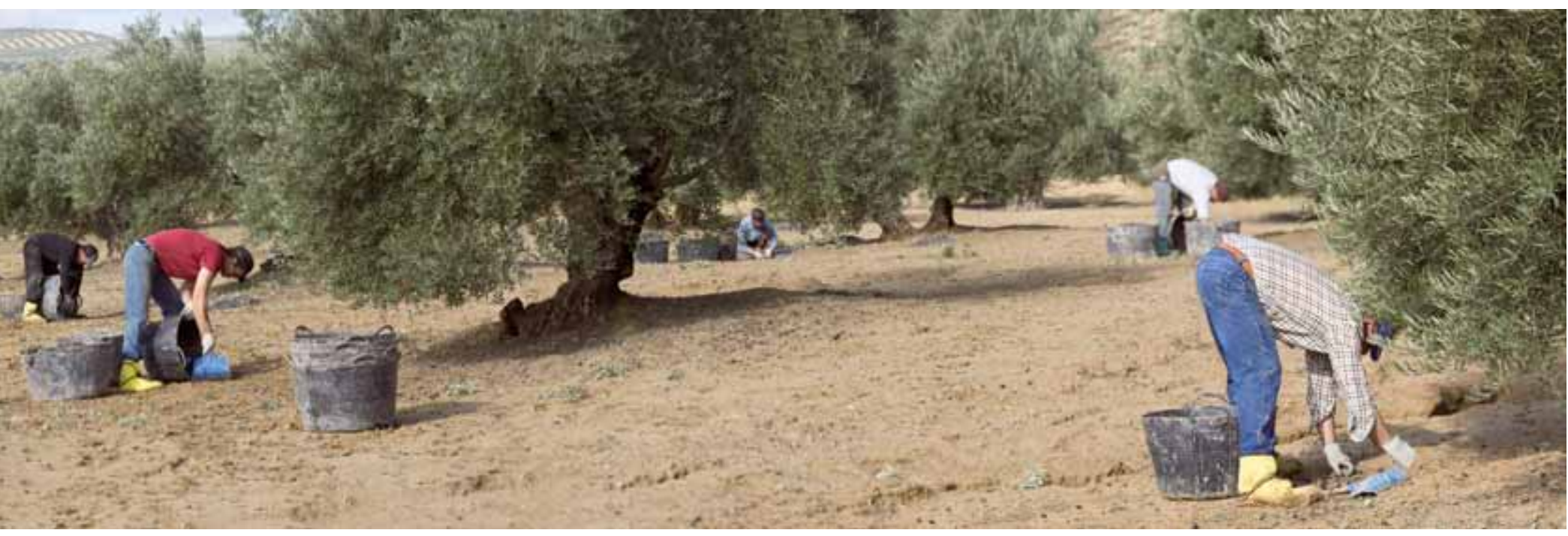

Recogida de la aceituna en Porcuna.

Fuente: Fondo Gráfico IAPH

La aportación urbana del Renacimiento crea espacios públicos que alteran las tramas hispanomusulmanas, configurando nuevas plazas, no ya para el mercado, sino para la exposición pública y el reconocimiento simbólico del poder individual a través de las grandes construcciones privadas en forma de palacios o templos-mausoleos, tal y como refleja la plaza Vázquez de Molina de Úbeda, o la plaza de Santa María de Baeza, donde es la nueva imagen del poder de las instituciones -Iglesia, Estado y Concejo- la que se pone de manifiesto con la moderna edilicia y que configura en ambas ciudades el paradigma del paisaje urbano renacentista del sur.

La cultura ilustrada propició una importante transformación territorial emprendida mediante la red de pueblos de colonización de Sierra Morena como La Carolina. La idea de progreso ilustrada, auspiciada bajo la nueva cultura del aprovechamiento agrícola, así como de la puesta en carga del territorio y la reforestación, aporta un nuevo orden territorial.

La condición de un sustrato geomorfológico específico en el piedemonte de Sierra Morena ha propiciado una cultura minera que puede percibirse hoy a través de los paisajes que se han ido conformando en distintos ciclos. Los paisajes mineros sembraron infraestructuras y equipamientos, incorporaron tecnología inédita e implantaron modos de vida y trabajo desconocidos en las zonas rurales, proyectando este territorio hacia el exterior. Son reflejo de la actividad extractiva que se desarrolló y tuvo su máximo esplendor en el siglo XIX, pero que arranca del II milenio a. de C. con un segundo ciclo en la época romana y con su posterior declive y desaparición en el siglo XX en el territorio de Linares. Hoy, esta cultura minera se hace perceptible a través de su paisaje al que se han incorporado como ruinas y vestigios las antiguas cabrias, estaciones, galerias, norias, etc. que esperan un futuro a través de nuevos e imaginativos usos.

Paisajes urbanos y territoriales que deben ser conservados desde un respeto a sus valores y desde una interpretación inte- ligente de sus posibilidades de uso presente, pues la función útil es lo que hace que aquellos fragmentos físicos e inmateriales del pasado que se conservan -aún vivos- sean valorados y preservados en las sociedades del presente, e incorporados al futuro desde la inteligencia compartida de sus habitantes. Sólo su valoración y uso desde nuevos sentidos permitirá su continuidad hacia el futuro.

\section{Nota}

'En fecha de elaboración de este número, Marcelino Sánchez Ruiz es alcalde de Úbeda.

\section{Bibliografía}

CASAS, C.; SÁNCHEZ, M. (1984) Asentamientos del Cobre Final-Bronce en la Loma de Úbeda. Arqueología Espacial. Teruel: Diputación general de Aragón y Diputación Provincial de Teruel, 1984

DOMínGUEZ A. (2002) Andalucia, ayer y hoy. Málaga: Sarria, 2002

MÁRQUEZ, F. (2004) La voz Andalucia. Enciclopedia General de Andalucía. Madrid: C\&T, 2004

MARTÍN. J.; SÁNCHEZ, M. (1994) La Comarca de la Loma. Madrid: Fundación Cultural Banesto, 1994 (Colección Patrimonio Medioambiental y Humano) NOCETE, F.; LIZCANO, R.; PERAMO A.; GÓMEZ, E. (2010) Emergence, collapse and continuity of the first political system in the Guadalquivir Basin from the fourth to the second millennium BC: The long-term sequence of Úbeda (Spain). Journal of Anthropological Archaeology, vol. 29, issue 2, 2010, pp. 219-237 SILVA PÉREZ, R.; OJEDA RIVERA, J. F. (2002) Aproximación a los paisajes de la Sierra Morena andaluza. En Paisaje y Ordenación del Territorio. Sevilla: Consejería de Obras Públicas y Transportes, 2002, pp. 71-91

W. AA. (2003) Informe de Justificación de Valores. Conjuntos Monumentales de Úbeda y Baeza. Enclave dual del Renacimiento Español. Sevilla: Consejería de Cultura, Junta de Andalucia, 2003

W. AA. (2010) Paisajes y Patrimonio Cultural en Andalucia. Tiempo, Usos e Imágenes. Vol.1. Sevilla: IAPH, Consejería de Cultura, 2010 